\title{
Study of Microalbuminuria and hs-CRP in Non-obese and Obese Normotensive and Hypertensive Males and Evaluation of Microalbuminuria and hs-CRP Changes according to the Stages of Hypertension \& Grades of Hypertensive Retinal Changes
}

\author{
A.G. Thivyah Prabha \\ Department of Biochemistry, East Point Hospital, India
}

Copyright $\bigcirc 2017$ by authors, all rights reserved. Authors agree that this article remains permanently open access under the terms of the Creative Commons Attribution License 4.0 International License

\begin{abstract}
Aims \& Objectives: To measure Microalbuminuria and hs-CRP in obese and non-obese male hypertensive patients and control groups and to correlate their levels with various stages of hypertension and different grades of hypertensive retinal changes. Men have higher prevalence of hypertension (29.4\%) than women (26.5\%)[1] Materials \& Methods: The study was conducted among 60 normotensive individuals and 60 hypertensive individuals over a period of 6 months on OPD basis. All individuals were males in the age group of 40-60 years. Blood samples were collected and estimation of plasma glucose, urea, creatinine, lipid profile, hs- CRP and Urinary microalbumin were done. Results: The mean value of microalbuminuria and hs- CRP were higher among obese hypertensives than obese controls and were statistically significant. The changes in the mean value of microalbuminuria and hs-CRP within the different stages of hypertension were highly significant. Similarly the correlation of microalbuminuria and hs-CRP within the different grades of hypertensive retinal changes were highly significant. Conclusion: The serum level of hs-CRP and urinary microalbuminuria were elevated in hypertensive patients. The increase of both hs- CRP and microalbuminuria were significantly higher in obese hypertensives than non-obese hypertensives. Microalbuminuria \& hs CRP levels correlate with various grades of hypertensive retinal changes.
\end{abstract}

Keywords Hypertension, hs-CRP, Microalbuminuria, Retinal Changes

\section{Introduction}

Hypertension is a common health problem and well known risk factor for cardiovascular diseases. Being clinically silent, it affects multiple organs and organ systems like kidney, brain and heart. Cardiovascular disease caused 2.3 million deaths in India in the year 1990; this is projected to be double by the year 2020. Epidemiological studies show that hypertension is directly responsible for $24 \%$ of $\mathrm{CHD}$ deaths. [2] Overweight and Obesity, the most common nutritional disorders are found worldwide and prevalence of these conditions in US ranks high in men $29.4 \%$ than women $26.5 \%$ in 2011-2014.[1]

Inflammatory processes play an important role in the vascular beds of hypertensive patients. The increasing levels of blood pressure may promote endothelial expression of cytokines and stimulates pro-inflammatory response in the arterial wall; thus resulting in vascular end-organ damage. [3] Obese individuals produce inflammatory markers referred as adipocytokines secreted by the adipose tissue under the influence of pro-inflammatory cytokines.[4] The most common available inflammatory marker of vascular endothelial damage are hs-CRP and microalbumin. hs-CRP is a well-known systemic marker of low grade inflammation that predicts future cardiovascular disease in apparently healthy subjects. [5] The American Heart Association and Centre for Disease Control and Prevention have recently issued a class IIa recommendation for measurement of CRP in primary prevention among those hypertensive patients at intermediate risk. Hs-CRP is also strongly associated with obesity and obesity related diseases like insulin resistance, DM and hyperlipidemia.CRP is also produced by cells in adipose tissue in response to inflammatory stimuli. [6] Urinary albumin excretion is seen in a large proportion of essential hypertensive patients, reflecting early endothelial damage in vascular tree of the kidney. Microalbuminuria is a condition with low but abnormal amount of albumin in 
urine.Microalbuminuria is an abnormal urinary excretion rate of albumin between the range of $30-300 \mathrm{mg} / \mathrm{g}$ creatinine.[7] Studies have shown that microalbuminuria is prevalent in $37.5 \%$ of patients with essential hypertension. The leakage in the glomeruli is probably due to general increase in capillary permeability of system vasculature. [8]

\section{Materials \& Methods}

The study was conducted among 134 males in the age group of 40-60years over a period of 6 months on OPD basis and 120 people were selected based on exclusion criteria. They were classified as normotensives and hypertensives based on JNC 8 classification as shown in table1.[9] Among them 60 were normotensive individuals and 60 were hypertensives. The normotensive group consisted of 30 non-obese $(\mathrm{BMI} \leq 24.9)$ and 30 obese $(\mathrm{BMI} \geq 25)$ subjects. The hypertensive group consisted of 30 non-obese (BMI $\leq 24.9$ ) and 30 obese (BMI $\geq 25$ ) subjects. EXCLUSION CRITERIA:All the participants had undergone a complete medical history with the following exclusion criterias like Diabetes mellitus, Prediabetes( FPG $100-125 \mathrm{mg} / \mathrm{dl}$ and PPPG 140-199 mg/dL ), Nephropathy (Creatinine >1.5 $\mathrm{mg} / \mathrm{l})$, Overt proteinuria and Active infection. INCLUSION CRITERIA: Male aged 40-60 yrs, non- smokers and nonalcoholics with hypertension and no other co-morbidities. The normotensives with blood pressure $\leq 120 / 80 \mathrm{mmHg}$ were selected as control group. Patients with hypertension were divided into three stages of hypertension according to JNC-8. Hypertensive retinal changes were studied using zeiss F450 fundus camera. The Keith -Wagener- Barker classification of retinal changes in hypertension based on general narrowing of arterioles, focal spasm, hemorrhage, exudates and papilledema were followed. The Keith Wagener- Barker classification of retinal changes in hypertension has been shown in table 2. [10]

A total of 120 samples were analysed from 60 normotensive and 60 hypertensive males of age group 40-60 yrs. The normotensive group of 60 subjects was divided into 30 non-obese individuals and 30 obese individuals. Similarly, the hypertensivegroup of 60 subjects were divided into 30 non-obese individuals and 30 obese individuals. Fasting plasma glucose, post prandial plasma glucose, cholesterol, TGL, HDL,LDL, urea, creatinine, hs- CRP and urinary microalbumin were analysed. The data was analysed using SPSS programme. The mean and SD were calculated for all the parameters. The significance between the groups was determined using t-test for equality of means. The $\mathrm{P}$ value $<$ 0.05 was considered as significant and indicated as * mark.

The blood samples were collected after overnight or 12 hours fasting in vacutainers for estimation. Blood samples were separated by centrifugation at $2400 \mathrm{rpm}$. Estimation of glucose [hexokinase method], [11] urea [urease method],[12] Creatinine[modified jaffes kinetic method], [13] lipid profile[direct enzymatic method] [14] and Urinary microalbumin [immunoturbidimetric method] [15] were done in Beckman coulter AU480. hs- CRP was done by immunoturbidimetricmethod. [16] For adequate quality control both normal and abnormal reference control solutions and calibrators were run before each batch. Other factors influencing quality like proper functioning of instrument, temperature, glassware, cuvettes and distilled water were taken care of properly before analysis.

Table 1. JNC 8 classification of hypertension

\begin{tabular}{|c|c|c|c|}
\hline CLASSIFICATION & SBP $[\mathbf{m m} / \mathbf{H g}]$ & AND & DBP $[\mathbf{m m} / \mathbf{H g}]$ \\
\hline Normal & $<120$ & OR & $800-89$ \\
\hline Prehypertension & $120-139$ & OR & $90-99$ \\
\hline Stage 1 HTN & $140-159$ & OR & $\geq 100$ \\
\hline Stage 2 HTN & $\geq 160$ & \\
\hline
\end{tabular}

Table 2. Keith -Wagener- Barker classification of retinal changes in hypertension

\begin{tabular}{|c|c|c|c|c|}
\hline Degree & General narrowing AV ratio (a) & Focal spasm(b) & Hemorrhage & Exudate \\
\hline Normal & $3: 4$ & $1: 1$ & 0 & 0 \\
\hline Grade I & $1: 2$ & $1: 1$ & 0 & 0 \\
\hline Grade II & $1: 3$ & $2: 3$ & 0 & 0 \\
\hline Grade III & $1: 4$ & $1: 3$ & + \\
\hline Grade IV & Fine fibrous cords & Obliteration of distal flow & + \\
\hline
\end{tabular}

(a) Ratio of arteriolar to venous diameter

(b) Ratio of diameter of region of spasm to proximal arteriole. 


\section{Results}

In the present study the mean and SD of physical parameters of control and hypertensives were shown in Table 3. BMI had significant difference on comparison of obese with non-obese control group. $\left[\mathrm{p}=0.000^{*}\right]$ The mean value of SBP and DBP of hypertensive group were significantly higher than control group. The comparison of physical parameters of non-obese controls with non-obese hypertensives showed high significance of SBP and DBP as shown in table 4.Similarly the comparison of physical parameters of obese controls with obese hypertensives had high significance of SBP and DBP as shown in table 5.

Table 3. Comparison of Physical Parameters Between Control and Hypertensive group

\begin{tabular}{|c|c|c|c|}
\hline PARAMETERS & $\begin{array}{c}\text { CONTROL } \\
\text { N=60 }\end{array}$ & $\begin{array}{c}\text { HYPERTENSIVE } \\
\mathbf{N}=\mathbf{6 0}\end{array}$ & P-VALUE \\
\hline AGE & $51.77( \pm 5.7)$ & $52.77( \pm 6.3)$ & 1.000 \\
\hline BMI & $25.45( \pm 5.7)$ & $24.87( \pm 3.6)$ & 1.000 \\
\hline SBP(mm Hg) & $116.17( \pm 8.6)$ & $160.85( \pm 18.2)$ & $0.000^{*}$ \\
\hline DBP(mm Hg) & $77.33( \pm 4.5)$ & $94.75( \pm 12.7)$ & $0.000^{*}$ \\
\hline
\end{tabular}

Table 4. Comparison of Physical Parameters of Non-Obese Control and Non-Obese Hypertensive Group

\begin{tabular}{|c|c|c|c|}
\hline PARAMETERS & $\begin{array}{c}\text { CONTROL } \\
\text { Non-Obese } \\
\text { N=30 }\end{array}$ & $\begin{array}{c}\text { HYPERTENSIVE } \\
\text { Non-Obese } \\
\text { N=30 }\end{array}$ & P-VALUE \\
\hline AGE & $51.67( \pm 6.0)$ & $52.75( \pm 6.2)$ & 1.000 \\
\hline BMI & $22.14( \pm 1.3)$ & $22.16( \pm 1.6)$ & 1.000 \\
\hline SBP (mm Hg) & $112.45( \pm 7.9)$ & $147.43( \pm 16.7)$ & $0.001^{*}$ \\
\hline DBP(mm Hg) & $76.64( \pm 4.8)$ & $90.51( \pm 9.5)$ & $0.001^{*}$ \\
\hline
\end{tabular}

Table 5. Comparison of Physical Parameters of Obese Control and Obese Hypertensive Group

\begin{tabular}{|c|c|c|c|}
\hline PARAMETERS & $\begin{array}{c}\text { CONTROL } \\
\text { Obese } \\
\mathbf{N = 3 0}\end{array}$ & $\begin{array}{c}\text { HYPERTENSIVE } \\
\text { Obese } \\
\mathbf{N}=\mathbf{3 0}\end{array}$ & P-VALUE \\
\hline AGE & $50.65( \pm 5.5)$ & $52.75( \pm 6.4)$ & 1.000 \\
\hline BMI & $28.81( \pm 6.5)$ & $27.52( \pm 3.1)$ & 1.000 \\
\hline SBP(mm Hg) & $119.35( \pm 9.4)$ & $174.32( \pm 19.2)$ & $0.001^{*}$ \\
\hline DBP(mm Hg) & $78.64( \pm 4.1)$ & $98.91( \pm 14.2)$ & $0.001^{*}$ \\
\hline
\end{tabular}

The comparison of biochemical parameters between controls and hypertensives were shown in table 6 . The mean of fasting plasma glucose and post prandial plasma glucose did not show significant difference, but the mean of T.cholesterol, LDL, TGL, microalbuminuria and hs-CRP were highly significant in hypertensive group. The mean of HDL was significantly lower in hypertensives than the controls.

Among the non-obese mean of fasting plasma glucose and post prandial plasma glucose did not show significant difference, but the mean of T.cholesterol, LDL and TGL were highly significant in obese hypertensive group. The mean of HDL was significantly lower in non-obese hypertensives than the controls. The mean value of microalbuminuria and hs- CRP in non-obese controls and hypertensives were highly significant. The comparison of biochemical parameters of non-obese controls and hypertensives were shown in table 7 .

Table 6. Comparison of Biochemical Parameters between Control and Hypertensive Group

\begin{tabular}{|c|c|c|c|}
\hline PARAMETERS & $\begin{array}{c}\text { CONTROL } \\
\mathbf{N}=\mathbf{6 0}\end{array}$ & $\begin{array}{c}\text { HYPERTENSIVE } \\
\mathbf{N}=\mathbf{6 0}\end{array}$ & P-VALUE \\
\hline FPG (mg/dL) & $89.62( \pm 11.6)$ & $92.44( \pm 11.0)$ & 0.751 \\
\hline PPPG (mg/dL) & $134.09( \pm 20.0)$ & $135.21( \pm 20.0)$ & 0.132 \\
\hline CHOL (mg/dL) & $167.73( \pm 28.4)$ & $213.11( \pm 39.0)$ & $0.001^{*}$ \\
\hline TGL (mg/dL) & $127.65( \pm 63.4)$ & $178.89( \pm 92.1)$ & $0.001^{*}$ \\
\hline HDL (mg/dL) & $44.52( \pm 6.5)$ & $34.61( \pm 5.6)$ & $0.001^{*}$ \\
\hline LDL (mg/dL) & $90.11( \pm 37.3)$ & $175.12( \pm 38.3)$ & $0.001^{*}$ \\
\hline Microalbuminuria (mg/L) & $12.80( \pm 5.9)$ & $37.80( \pm 21.8)$ & $0.000^{*}$ \\
\hline hs-CRP (mg/dL) & $0.27( \pm 0.17)$ & $0.73( \pm 0.73)$ & $0.000^{*}$ \\
\hline
\end{tabular}

Table 7. Comparison of Biochemical Parameters between Non-Obese Control and Non-Obese Hypertensive Group

\begin{tabular}{|c|c|c|c|}
\hline PARAMETERS & $\begin{array}{c}\text { CONTROL } \\
\mathbf{N}=\mathbf{3 0}\end{array}$ & $\begin{array}{c}\text { HYPERTENSIVE } \\
\mathbf{N}=\mathbf{3 0}\end{array}$ & P-VALUE \\
\hline FPG (mg/dL) & $87.62( \pm 10.7)$ & $89.19( \pm 10.7)$ & 0.781 \\
\hline PPPG (mg/dL) & $132.13( \pm 20.6)$ & $126.67( \pm 13.6)$ & 0.589 \\
\hline CHOL $(\mathbf{m g} / \mathbf{d L})$ & $144.67( \pm 43.0)$ & $171.87( \pm 18.3)$ & $0.021^{*}$ \\
\hline TGL (mg/dL) & $107.82( \pm 67.5)$ & $156.37( \pm 92.2)$ & $0.046^{*}$ \\
\hline HDL $(\mathbf{m g} / \mathbf{d L})$ & $46.34( \pm 7.4)$ & $38.18( \pm 4.9)$ & $0.007^{*}$ \\
\hline LDL $(\mathbf{m g} / \mathbf{d L})$ & $87.11( \pm 9.2)$ & $151.68( \pm 32.7)$ & $0.002^{*}$ \\
\hline Microalbuminuria (mg/L) & $12.63( \pm 5.8)$ & $25.53( \pm 13.3)$ & $0.000^{*}$ \\
\hline hs-CRP $(\mathbf{m g} / \mathbf{d L})$ & $0.19( \pm 0.16)$ & $0.50( \pm 0.57)$ & $0.000^{*}$ \\
\hline
\end{tabular}


Among the obesecontrol and obese hypertensive subjects comparison of biochemical parameters showed a significant difference as shown in table 8. The mean of T.cholesterol, LDL and TGL were highly significant in obese hypertensives and the mean of HDL was significantly lower in obese hypertensives than the controls. The mean value of microalbuminuria and hs-CRP in obese control and hypertensive groups were highly significant. Comparison of microalbuminuriain non-obese \&obese control and hypertensive groups were shown in figure1. Comparison of hs-CRP in non-obese \& obese control and hypertensive groups were shown in figure 2 .

Table 8. Comparison of Biochemical Parameters between Obese Control and Obese Hypertensive Group

\begin{tabular}{|c|c|c|c|}
\hline PARAMETERS & $\begin{array}{c}\text { CONTROL } \\
\mathbf{N}=\mathbf{3 0}\end{array}$ & $\begin{array}{c}\text { HYPERTENSIVE } \\
\mathbf{N}=\mathbf{3 0}\end{array}$ & P-VALUE \\
\hline FPG (mg/dL) & $91.53( \pm 12.6)$ & $95.80( \pm 11.5)$ & 0.442 \\
\hline PPPG (mg/dL) & $136.81( \pm 9.4)$ & $139.77( \pm 15.5)$ & 0.496 \\
\hline CHOL $(\mathbf{m g} / \mathbf{d L})$ & $189.93( \pm 37.3)$ & $256.23( \pm 27.6)$ & $0.001^{*}$ \\
\hline TGL $(\mathbf{m g} / \mathbf{d L})$ & $147.63( \pm 59.6)$ & $202.27( \pm 87.5)$ & $0.001^{*}$ \\
\hline HDL $(\mathbf{m g} / \mathbf{d L})$ & $42.70( \pm 5.5)$ & $31.70( \pm 6.0)$ & $0.002^{*}$ \\
\hline LDL $(\mathbf{m g} / \mathbf{d L})$ & $94.30( \pm 22.3)$ & $198.07( \pm 43.3)$ & $0.001^{*}$ \\
\hline Microalbuminuria (mg/L) & $13.08( \pm 6.1)$ & $48.46( \pm 22.7)$ & $0.000^{*}$ \\
\hline hs-CRP $(\mathbf{m g} / \mathbf{d L})$ & $0.35( \pm 0.16)$ & $0.96( \pm 0.81)$ & $0.000^{*}$ \\
\hline
\end{tabular}

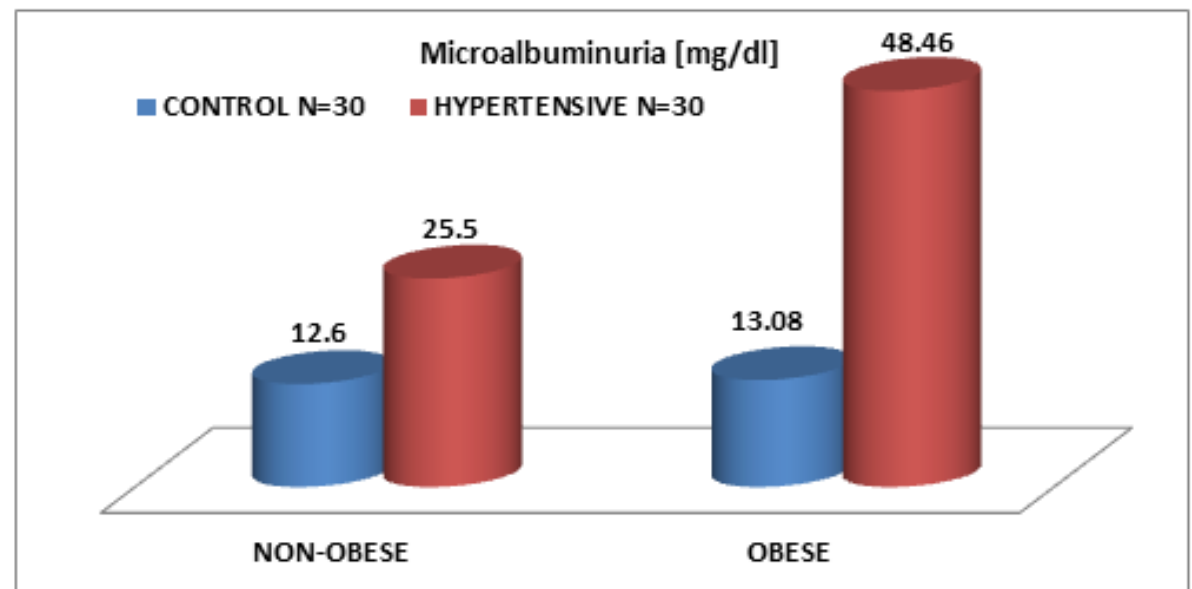

Figure 1. Comparison of Microalbuminuriabetween Non-obese \&Obese Control and Hypertensive Group.

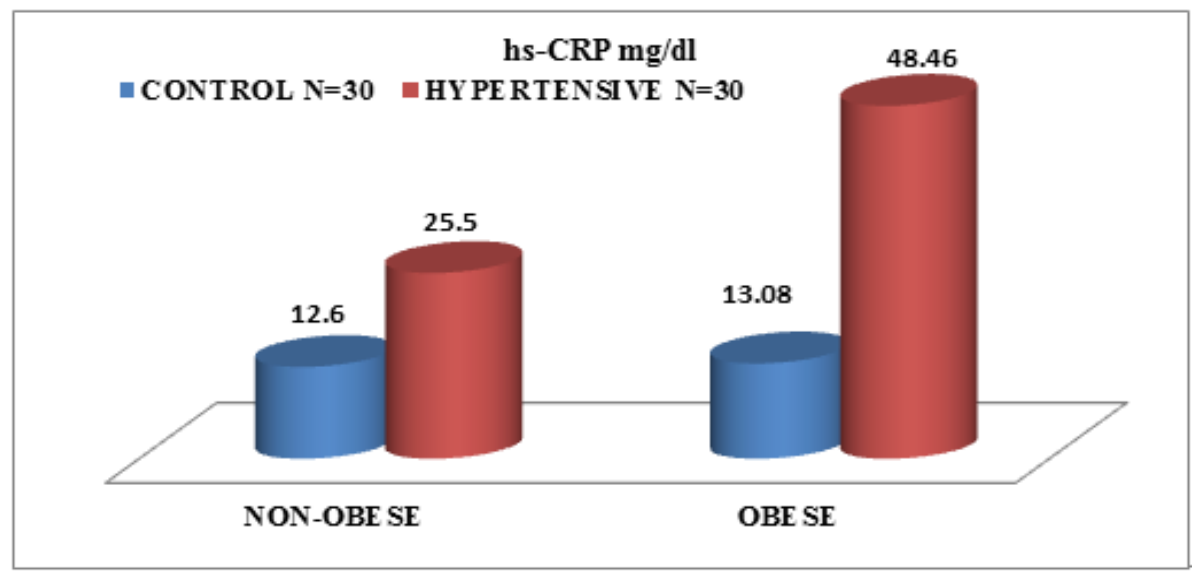

Figure 2. Comparison of hs-CRP between Non-obese \& Obese Control and Hypertensive Group 
Number of cases in stage preHT, I and II of hypertension were 12,36 and 12 respectively. The comparison of mean values of microalbuminuria and hs-CRP in various stages of hypertension were shown in table 9 and figure $3 \& 4$. Microalbuminuria and hs- CRP values had significant increase according to the stages of HT and the values were increasing proportionately.
Table 10 shows the number of cases with hypertensive retinal changes, according to the grades. Out of 60 hypertensive subjects $24,17,13$ and 6 were in grade 0 , grade 1 , grade II and grade III. The comparison of microalbuminuria and hs-CRP according to the grades of HRC indicates a significant increase and were significant statistically.[pvalue 0.000]

Table 9. Comparison of Microalbuminuria \& hs-CRP in various Stages of Hypertension

\begin{tabular}{|c|c|c|c|c|}
\hline PARAMETERS & $\begin{array}{c}\text { STAGE Pre HTN } \\
\mathrm{N}=12\end{array}$ & $\begin{array}{c}\text { STAGE I HTN } \\
\mathbf{N}=\mathbf{3 6}\end{array}$ & $\begin{array}{c}\text { STAGE II HTN } \\
\mathrm{N}=12\end{array}$ & P-VALUE \\
\hline Microalbuminuria (mg/L) & $24.93( \pm 10.04)$ & $34.90( \pm 18.76)$ & $55.23( \pm 27.94)$ & $0.001^{*}$ \\
\hline hs-CRP (mg/dL) & $0.56( \pm 0.091)$ & $0.60( \pm 0.46)$ & $1.27( \pm 1.00)$ & $0.014^{*}$ \\
\hline
\end{tabular}

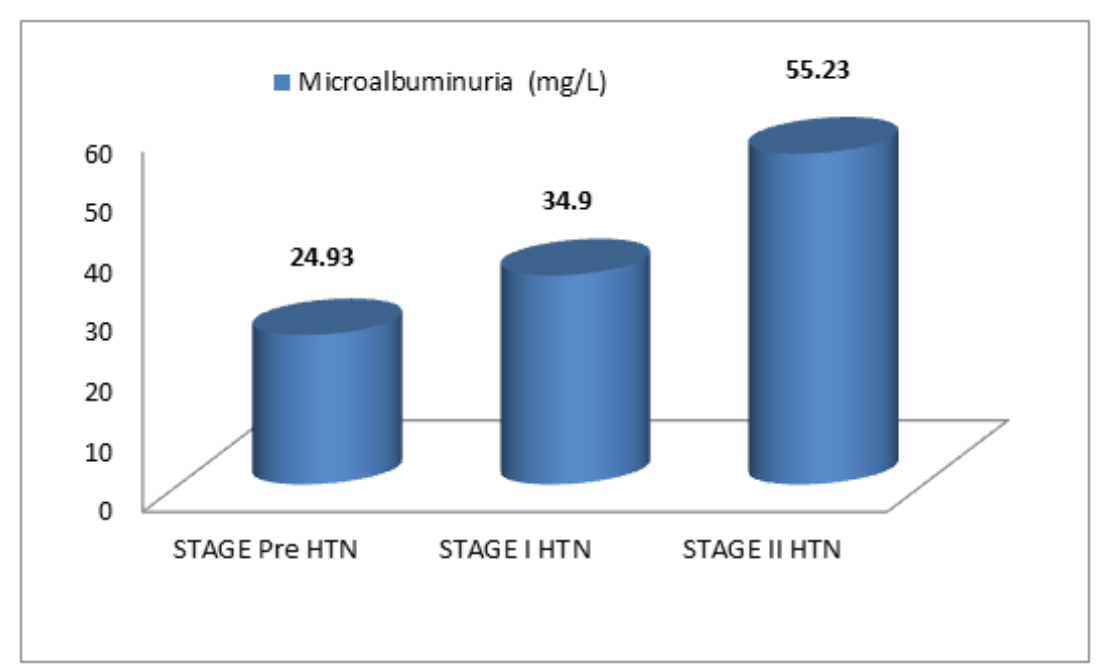

Figure 3. Comparison of Microalbuminuriain various Stages of Hypertension

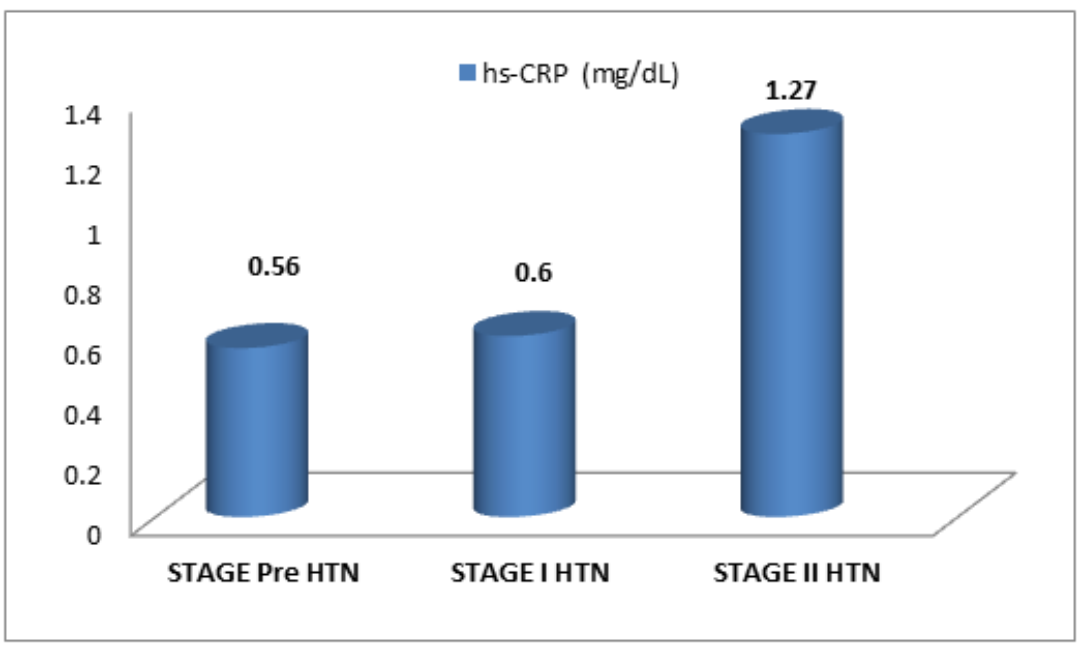

Figure 4. Comparison ofhs-CRPin various Stages of Hypertension

Table 10. Comparison of Microalbuminuria\&hs-CRPin various Grades of Hypertensive Retinal changes (HRC).

\begin{tabular}{|c|c|c|c|c|c|}
\hline PARAMETERS & $\begin{array}{c}\text { GRADE 0 } \\
\mathbf{N}=\mathbf{2 4}\end{array}$ & $\begin{array}{c}\text { GRADE 1 } \\
\mathbf{N}=\mathbf{1 7}\end{array}$ & $\begin{array}{c}\text { GRADE 2 } \\
\mathbf{N}=\mathbf{1 3}\end{array}$ & $\begin{array}{c}\text { GRADE 3 } \\
\text { N=6 }\end{array}$ & P-VALUE \\
\hline $\begin{array}{c}\text { Microalbuminuria } \\
\text { (mg/L) }\end{array}$ & $15.78( \pm 9.46)$ & $36.92( \pm 16.75)$ & $46.36( \pm 19.03)$ & $72.23( \pm 21.92)$ & $0.000^{*}$ \\
\hline hs-CRP (mg/dL) & $0.32( \pm 0.38)$ & $0.64( \pm 0.40)$ & $1.28( \pm 1.01)$ & $0.92( \pm 0.28)$ & $0.000^{*}$ \\
\hline
\end{tabular}




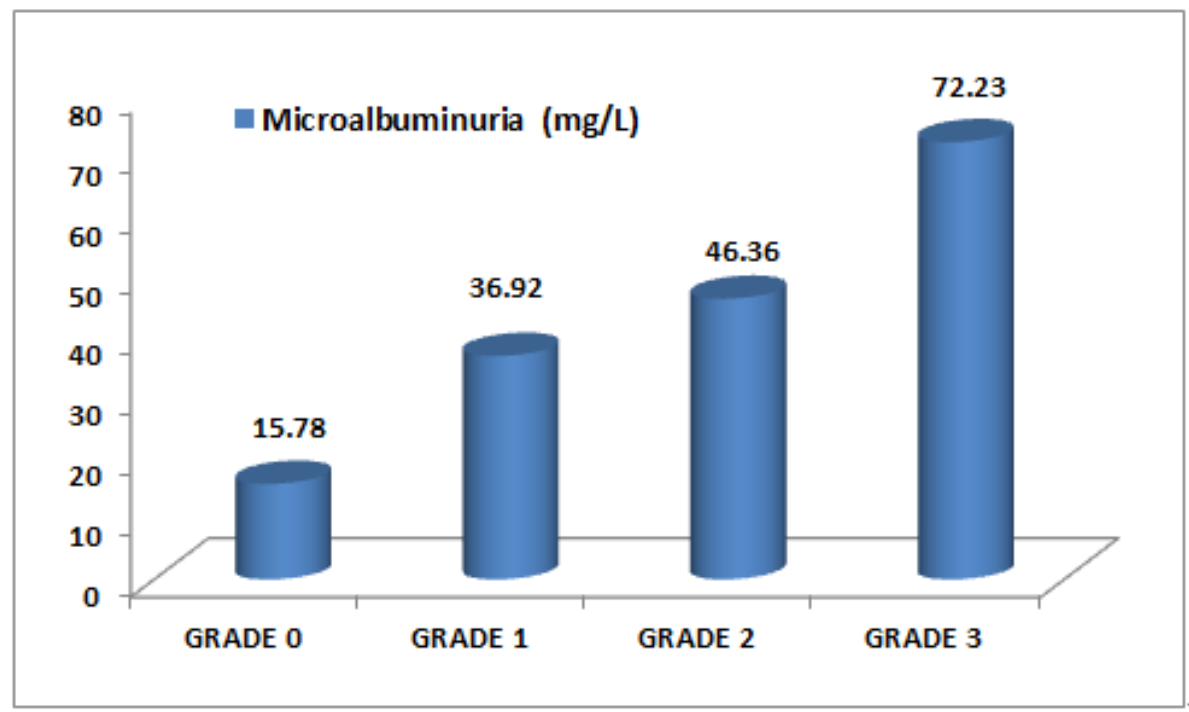

Figure 5. Comparison of Microalbuminuriain various Grades of Hypertensive Retinal changes (HRC).

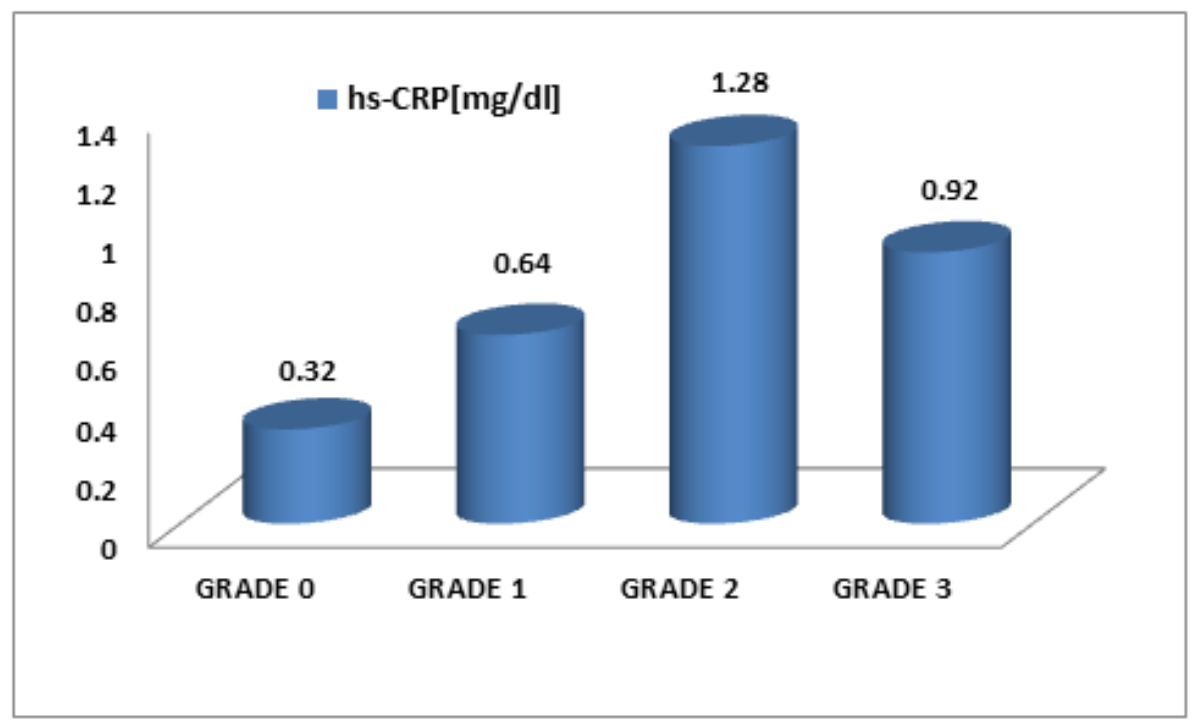

Figure 6. Comparison of hs-CRP in various Grades of Hypertensive Retinal changes (HRC).

In stage preHT, 10 cases were reported in grade 0 and 2 cases in grade I. Out of 36 subjects in stage I hypertension $14,13,8$ and 1 cases were reported with grade 0 , grade I, grade II and grade III of hypertensive retinal changes which had significant difference within the group. Out of 12 subjects in stage III hypertension 2,5 and 5 cases were reported in grade I, grade II and grade III of hypertensive retinal changes and the $\mathrm{p}$ value was not significant.. Comparison of Microalbuminuriain \& hs CRP in various Grades of Hypertensive Retinal changes (HRC) were shown in figure $5 \& 6$.

\section{Discussion}

Several studies have shown C-reactive protein as an early biomarker of inflammation and urinary microalbumin as an early indicator of endothelial dysfunction. Roberto Pedrinelli studied albuminuria and CRP as markers of systemic low-grade inflammation, which are frequently elevated in essential hypertensive patients without overt cardiovascular and renal diseases. Moreover the two parameters were high in individuals with greater BMI.[3]

In the present study, the physical parameters were compared between non-obese and obese individuals of the control group. BMI showed a significant difference, but other parameters SBP and DBP did not show significant difference between non-obese and obese controls. The physical parameters were compared between non-obese hypertension and obese hypertensives. BMI was significant statistically [ $p$ value $=0.000$ ] among them. The mean value of SBP\& DBP of obese hypertensives were significantly higher than non-obese hypertensives.

Many studies suggest that abdominal obesity is more closely associated with high BP. According to Framingham cohort [17] obesity accounts for $78 \%$ and $65 \%$ of essential 
Hypertension in men and women. Elevated BP due to obesity can cause long term damage to the body's vital organs and functions.[18] Furthermore, obesity causes the endothelium to be exposed to mechanical forces and cardiovascular risk factors that alters vascular structure and function. Thus there is evidence that obesity is associated with peripheral and coronary endothelial dysfunction.[19]

The biochemical parameters between the control and hypertensive group were compared. The mean value of T.cholesterol, TGL and LDL were significantly higher than the control group. Barbara Glowinska et al studied serum profile in hypertensive patients. The result had abnormal pattern in total cholesterol, TGL and LDL in hypertensives that proved to cause atheromatous changes in blood vessels. Normally, HDL c is formed from catabolism of TGL rich lipoproteins. In hypertensives there is a reduction in the fractional rate of removal of endogenous TGL. Thus serum HDLc levels are reduced .[20] Obese individuals are associated with increased abdominal fat which results in increased fatty acid release, thus leads to hypertriglyceridemia. Thereby, obese hypertensive patients have reduced HDLc due to increase of triglycerides.[21,17]

The mean of microalbuminuria in hypertensives was highly significant than the control group and the increase was statistically significant. Essential hypertensive patients have increased albuminuria than normotensives. The increased urinary albumin excretion in hypertension represents the long term hemodynamic overload. This study has also shown the association between urinary albumin excretion with cardiac mass and increased vascular resistance.[22] Microalbuminuria was compared between non-obese and obese hypertensives which showed a significant difference.[p value 0.000] Andreasdis et al [23] shown the increase of microalbuminuria in obese hypertensive patients and strongly suggested that microalbuminuria is associated with central obesity, insulin resistance ,low HDL c, high TGL and systolic hypertension.[24] hs-CRP was significantly higher in hypertensive group than the control group. A prospective cohort study by Yasmin GM et al in female aged 45 yrs or older have proved the association of CRP with hypertension. As comparison of hs-CRP between non-obese and obese control had significant difference, comparison was made between non-obese control and non-obese hypertensives as well as obese control and obese hypertensives and it was statistically significant. Obesity especially abdominal obesity is associated with elevations of hs-CRP. It is of pathogenic significance as it stimulates the uptake of LDL by macrophages and induces complement system which causes cellular damage in the artery and enhances monocyte production of tissue factor and increases the risk of thrombosis.[25]Hence hs -CRP is a marker of vascular inflammation; linking hypertension to vascular disease.[26-29] CRP has gained much attention by the Framingham Risk Score which suggested that CRP was significantly $\mathrm{a}$ better and strong predictor of future cardiovascular events than LDLc. [30] CRP's predictive power for vascular risk detection resides between 0.1-0.5 $\mathrm{mg} / \mathrm{dL}$, a level which is present in most of the healthy individuals without inflammation; hence a high sensitive assay was used. hs-CRP values $<1 \mathrm{mg} / \mathrm{L}$ is considered as low risk, $1-3 \mathrm{mg} / \mathrm{L}$ as intermediate risk and $>3 \mathrm{mg} / \mathrm{L}$ as high risk. The North American Association for the study of obesity showed a positive correlation of hs-CRP with obesity. The results were significantly related to the presence of metabolic syndrome, hyperlipidemia and hypertension. Furthermore, changes in hs-CRP were related to changes in weight, thus supporting the hypothesis: life style modification reduces inflammation and risk of CHD.[31]

Out of 60 cases of hypertension, 12 cases were in stage pre-HT, 36 cases were in stage I and 12 in stage II hypertension respectively. The comparison of mean of microalbuminuria has significant difference between the groups with $p$ value $(0.001)$ The degree of microalbuminuria shows positive correlation with stages of hypertension. The findings of elevated urinary albumin excretion, correlating with BP levels in insufficiently treated essential hypertension has been shown in a study.[21] The mean of hs-CRP in stage II hypertension is significantly higher than stage Pre-HT and I hypertension( $\mathrm{p}$ value 0.014). The link between BP and vascular inflammation has been correlating with other studies. The result showed elevation of CRP levels with increasing stages of BP to be a strong independent determinant of future cardiovascular events. Another data suggests that CRP plays a direct role in promoting hypertension.

Comparison of the mean value of microalbuminuria in each grades of hypertensive retinal changes(HRC) were proportionately increasing. Grade III HRC showed significantly higher value than other grades of HRC. The comparison between the groups is significant statistically. $p$ value 0.000 ) Microalbuminuria is a marker of target organ damage in essential hypertensives that reflects endothelial dysfunction. The Beaver Dam Eye Study and the Blue Mountains Eye Study provided the increased rate of prevalence of retinal changes in hypertensives. [32] Dodson PM et al studied the clinical significance of stratifying cardiovascular risk in hypertensive patients on the basis of retinal changes. The result of high prevalence of retinal changes with microalbuminuria in hypertension.[33]

Comparison of mean values of hs -CRP in each grades of HRC shows an increase in hs- CRP as the grades of HRC increases. But there is small decrease in grade III in comparison to grade II but this could not be considered because of very less number of case in grade III group.

Several clinical studies suggested that, the extent of retinal vascular changes including retinopathy reflects the severity and duration of hypertension. The MAGIC study had proved the relationship between microalbuminuria and presence of retinopathy and ECG abnormalities in hypertensive patients. Major ECG abnormalities and vascular retinal changes are thought to reflect pressure overload and atherosclerotic vascular damage in essential hypertension patient and thus 
considered as predictors of future vascular events.[34]

\section{Conclusions}

The serum level of hs-CRP, an early marker of low grade systemic inflammation is significantly elevated in hypertensive group. Urinary Microalbuminuria concentration, an early marker of endothelial dysfunction is significantly elevated in hypertensive group. The increase of both hs- CRP and microalbuminuria were significantly higher in obese hypertensives than non-obese hypertensives. Microalbuminuria \& hs-CRP levels correlate with various grades of hypertensive retinal changes.

\section{REFERENCES}

[1] U.S. Department of Health and Human Services, Office of Disease Prevention and Health Promotion. Healthy People 2020. Available from:

http://www.healthypeople.gov/2020/default.aspx.

[2] Wolz M. Prevalence of hypertension. National Heart lung and Blood institute.

[3] Roberto Pedrinelli, Giulia Dell' Omo, Vitantonio Di Belloet al. Low grade Inflammation and Microalbuminuria in Hypertension. Atherosclerosis, thrombosis and vascular Biology.2004; 24: 2414.

[4] Stevens VJ, ObarzanekE,Cook NO et al. Long term weight loss and changes in blood pressure. Result of the Trials of Hypertension Prevention, phase II. Ann intern Med. 2001; 134: $1-11$.

[5] Yudkin JS, Stehouwer CDA, Emeis JJ and Coppack SW.C-reactive protein in healthy subjects: Associations with obesity, insulin resistance and endothelial dysfunction. Arterioscler Thromb Vasc Biol.1999; 19: 972-978.

[6] Kuller LH, Shaten J. Relationship of RP and coronary heart disease in the MRFIT nested case- control study. American journal of epidemiology. 1996; 144: 537-547.

[7] PedrinelliR,Dell'Omo G, Di Bello V, Ponremoli R and Marianui M. Microalbuminuria, an integrated marker of cardiovascular risk in essential hypertension. J Hum Hypertens.2002; 16: 79-89.

[8] YudkinJS,Forrest RD, Jackson CA. Microalbuminuria as predictor of vascular disease in non- diabetic subjects. Lancet. 1988; 2 : 530-533.

[9] Saseen JJ, MacLaughlin. Hypetension. In: DiPiro JT, Talbert RL, Yee GC, Matzke GR, Wells BG, Posey LM, editors. Pharmacotherapy: A pathophysiologic approach. 9th ed. New York: McGraw-Hill Medical; c2014. Chapter 3.JNC 8

[10] Keith NM,WagenerHP,BarkerMW.Some different types of essential hypertension:their course and prognosis. Am J Med Sc. $1939 ; 197:$ 332-343.

[11] Czok R, Barthelmai W. EnzymatischeBestimmungen der Glucose in Blut, Liquor und Harn. KlinWschr 1962; 40: 585-589.
[12] Talke H, Schubert GE. Enzymatischeharnstoffbestimmung in blut und serum imoptischen test nach Warburg. KlinWochenschr 1965; 43: 174-75.

[13] Cook JGH. Creatinine assay in the presence of protein. Clin Chim Acta. 1971; 32: 485-6.

[14] Allain CC, Poon LS, Chan CSG, Richmond W, Fu PC. Enzymatic determination of total serum cholesterol. Clin Chem 1974; 20: 470-475.

[15] Sacks DB. Carbohydrates. In: Burtis CA, Ashwood ER, eds. Tietz textbook of clinical chemistry. Philadelphia: WB Saunders Company, 1999; 798pp.

[16] Whicher J. C-reactive protein (CRP). In: Thomas L, ed. Clinical laboratory diagnostics. Use and assessment of clinical laboratory results. Frankfurt/Main: TH-Books Verlagsgesellschaft, 1998:700-706.

[17] Kannel et al. Risk stratification in hypertension: new insight from Framingham study. American journal of Hypertension. 2000; 13: 35-105.

[18] Reisen E, Abel R, Modan M et al. Effect of weight loss without salt restriction on the reduction of BP in overweight hypertensive patients. NEJM.1978; 198: 1-6.

[19] Lycon CJ, Law RE, hsueh WA. Inflammation and atherogenesis. Adiposity, Endocrinology. 2003; 144: 2195-2200.

[20] Barbara Glowinska et al. New atherosclerosis risk factors in obese, hypertensive and diabetic children and adolescents. Atherosclerosis.2003; 167: 275-286.

[21] Alexander J, Dustan HP, Sims EAH et al. Report of hypertension Task Force, US Department of Health, Education and Welfare Publication 70-1631(NIH). Washington,DC,US Government printing Office.1997;61-77.

[22] Woo J, Cockram CS, Swaminathan R, Lau E, Chan A, Cheung R. Microalbuminuria and other cardiovascular risk factors in non diabetic subjects. Int J Cardiol.1992; 37: 345-350.

[23] Andreadis E, Tsourous G, VassilopoulousC, Kakou M. Microalbuminuria in overweight and obese hypertensives. American Journal of hypertension. 2004; 17: 210.

[24] Damsgaard EM, Froland A, Jorgensen OD, Mogensen CE. Microalbuminuria as predictor of increased mortality in elderly people. Br Med J. 1990; 300: 297-300.

[25] Yasmin GM et al. Association between BP and CRP among apparently healthy US adults. Circulation. 2002;39: 197-202.

[26] Pasceri V, Chang J, Willerson et al. Modualtion of CRP mediated monocyte chemoattractant protein -1 induction of human endothelial cells. 2 Circulation. 2001; 103: 2531-34.

[27] Wang CH,LiSH, Weisel et al. CRP upregulates angiotensin type 1 receptors in VSMC. Circulation. 2003;107;1783-1790.

[28] LiSH, Szmittee, Weisel RD, etal. CRP upregulates complementary inhibitory factors in endothelial cells. Circulation. 2003.

[29] Wung BS, Cheng JJ, Chao YZ et al. Cyclic strain increases MCP-1 secretion in human endothelial cells. American journal of Physiology.1998; 270: 1462-1468. 
[30] Froehlich M, imhof A, Bergh et al. Association between CRP and features of metabolic syndrome a population based study. Diabetes care. 2000; 23: 1835-1839.

[31] Ridker PM, Rifai,Rose L et al. Comparison of CRP and LDL c levels in prediction offirst cardiovascular events. NEJM. 2002; 347: $1557-1565$.

[32] Lip GYH, Beevers M. Survival and prognosis of 315 patients with malignant phase hypertension. Journal of hypertension. 1995; 13: 915-924.
[33] Dodson PM et al. Hypertensive retinopathy: a review of existing classification system and a suggestion for a simplified grading system. Journal of human Hypertension.1996; 10: 93-98.

[34] Robert Pontremoli, Antonella Sofia, Maura Ravera, Clizia Nicolella et al. Prevalence and clinical correlates of microalbuminuria in essential hypertension. The MAGIC study. American heart Association.1997. 